\title{
The Biosynthesis of Tetrahymanol in vitro
}

\author{
By E. Caspi, J. B. Greig and J. M. Zander \\ The Worcester Foundation for Experimental Biology, Shrewsbury, Mass. 01545, U.S.A.
}

(Received 29 July 1968)

We have recently shown (Caspi et al. 1968) that, when the protozoan Tetrahymena pyriformis is grown on a medium containing $\left[{ }^{14} \mathrm{C}\right]$ squalene and [ $\left.{ }^{3} \mathrm{H}\right]$ squalene 2,3-oxide, a triterpene metabolite, tetrahymanol (Ia) (Tsuda et al. 1965; Mallory, Gordon \& Conner, 1963), contains considerable ${ }^{14} \mathrm{C}$ radioactivity but is essentially devoid of ${ }^{3} \mathrm{H}$. This was taken as evidence that the biosynthesis of tetrahymanol involves a proton-initiated cyclization of squalene, terminated by nucleophilic hydroxylation at C-21. Such a pathway has been suggested for this (Tsuda et al. 1965) and other 3-deoxytriterpenes (Halsall \& Aplin, 1965; Barton, de Mayo \& Orr, 1958), and is in direct contrast with that found in mammalian and other systems, for which squalene 2,3-oxide has been shown to be a precursor of sterols and triterpenes (Corey, Russey \& Ortiz de Montellano, 1966; van Tamelen, Willett, Clayton \& Lord, 1966; Godtfredsen, Lorck, van Tamelen, Willett \& Clayton, 1968; Rees, Goad \& Goodwin, 1968).

However, the possibility existed that the squalene 2,3-oxide had been inactivated, possibly by conversion into the 2,3-glycol (cf. Clayton, van Tamelen \& Nadeau, 1968), before its penetration to the intracellular site of tetrahymanol biosynthesis; attempts to recover this oxide from the saponified cells afforded only small quantities of impure material. We have therefore repeated the above experiment with a disrupted cell preparation and a milder work-up procedure. The results described below confirm and extend our previous findings.

Tetrahymena pyriformis type W, A.T.C.C. 10542, was grown in 11 . cultures. The medium contained

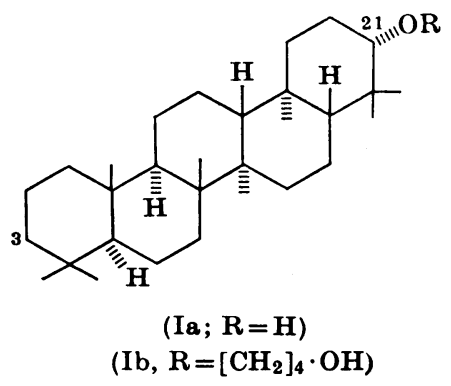

the following ingredients (concentrations in g./l.): Proteose-Peptone (Difco Laboratories Inc., Detroit, Mich., U.S.A.), 5•0 ; Bacto-Tryptone (Difco Laboratories Inc.), 5.0; D-glucose, 10.0; sodium acetate trihydrate, $1 \cdot 0 ; \mathrm{KH}_{2} \mathrm{PO}_{4}, 0 \cdot 5$. The $\mathrm{pH}$ was adjusted to $7 \cdot 1$ with aq. $\mathrm{NaOH}$ before sterilization. After a growth period of $42 \mathrm{hr}$. at $25-26^{\circ}$ the protozoa from $5 \cdot 41$. of medium were harvested by centrifugation (400 $\mathrm{g}$ for $15 \mathrm{~min}$.), washed twice with dilute Ringer phosphate medium (Ryley, 1952) and freeze-dried (Hogg \& Kornberg, 1963).

The resultant powder $(1 \cdot 6 \mathrm{~g}$.) was suspended in dilute Ringer phosphate medium $\left(40 \mathrm{ml}\right.$.) at $0^{\circ}$ by means of a Potter-Elvehjem homogenizer. To this enzyme preparation was added a mixture of $\left[{ }^{14} \mathrm{C}\right]$ squalene (approx. $2.6 \times 10^{5}$ disintegrations $/ \mathrm{min}$.) and $\left[{ }^{3} \mathrm{H}\right]$ squalene 2,3 -oxide (approx. $1.3 \times 10^{6} \mathrm{dis}-$ integrations/min.), ${ }^{3} \mathrm{H} /{ }^{14} \mathrm{C}$ ratio $4 \cdot 81$, suspended in water with Triton X-100. [For the preparation of these substrates see Caspi et al. (1968).] After incubation for $3 \mathrm{hr}$. at $25^{\circ}$, the incubation mixture was divided into two equal portions, one of which was saponified with aq.-methanolic $\mathrm{KOH}$ and extracted with hexane. Preparative thin-layer chromatography of the hexane extract on silica gel with methylene chloride-acetone $(19: 1, v / v)$ as the mobile phase afforded [14C]tetrahymanol, $R_{F} \mathbf{0 . 4 1}$ (2.4\% incorporation). Co-crystallization from ethanol followed by Jones oxidation (Bowden, Heilbron, Jones \& Weedon, 1946) gave tetrahymanone (Mallory et al. 1963) having a ${ }^{3} \mathrm{H} /{ }^{14} \mathrm{C}$ ratio 0.027 . (The very small percentage of ${ }^{3} \mathrm{H}$ indicated lies within the range of variations of the background count.)

The second portion of the incubation mixture was deproteinized with a boiling ethanol-diethyl ether $(3: 1, v / v)$ mixture and a hexane extract obtained (cf. Cornforth, Cornforth, Pelter, Horning \& Popják, 1959). The extract, after preparative thin-layer chromatography on silica gel [twofold development with hexane-ethyl acetate $(9: 1, v / v)]$, was resolved into bands corresponding to squalene, $R_{F} \mathbf{0 . 9 0}$, squalene 2,3-oxide, $R_{F} \mathbf{0 . 5 5}$, and tetrahymanol, $R_{F} \mathbf{0} \cdot 16$. Each zone was then extracted with benzene.

The squalene fraction $\left(55 \%\right.$ recovery of ${ }^{14} \mathrm{C}$ radioactivity) was diluted with unlabelled material and purified via the thiourea clathrate (Goad \& Goodwin, 1966) and by preparative thin-layer 
chromatography. The resulting material contained only ${ }^{14} \mathrm{C}$ radioactivity.

The zone containing squalene 2,3-oxide (41\% recovery of ${ }^{3} \mathrm{H}$ radioactivity), after dilution and purification by repeated preparative thin-layer chromatography, was found to be devoid of ${ }^{14} \mathrm{C}$ radioactivity. The identity of this material was further confirmed by hydrolysis to $\left[{ }^{3} \mathrm{H}\right]$ squalene 2,3-glycol (van Tamelen \& Curphey, 1962).

The tetrahymanol fraction $\left({ }^{14} \mathrm{C}\right.$ incorporation $12 \%$ ) was extensively purified by thin-layer chromatography, co-crystallization and sublimation, and was then acetylated. The resulting tetrahymanol acetate retained a substantial amount of ${ }^{3} \mathrm{H}$-labelled impurity. This impurity was removed by saponification of the acetate and treatment of the crude product with periodic acid in ether-tetrahydrofuran $(1: 3, v / v)$. Thin-layer chromatography followed by crystallization from acetone afforded the tetrahymanyl monoether of butane-1,4-diol $(\mathrm{Ib}),{ }^{3} \mathrm{H} /{ }^{14} \mathrm{C}$ ratio $0 \cdot 014$. (The very small percentage of ${ }^{3} \mathbf{H}$ indicated lies within the range of variations of the background count.)

The structure of this ether, m.p. 229-233, follows from its mass spectrum: $m / e 498\left(M^{+}-2 \mathrm{H}\right.$; cf. Budzikiewicz, Djerassi \& Williams, 1967), 427 $\left(M^{+}-\mathrm{C}_{4} \mathrm{H}_{9} \mathrm{O}\right)$ and $413,410,395$ and 191 (cf. tetrahymanol: $m / e$ 428, 413, 410, 395 and 191); and from its infrared spectrum, which was very similar to that of tetrahymanol, but showed increased intensity of absorption at $1040 \mathrm{~cm} .^{-1}$ (C-O stretching), in addition to some minor differences in the fine structure. Further, after treatment of this ether with refluxing hydriodic acid, it was possible to reisolate tetrahymanol.

In a separate experiment a freshly prepared powder of the protozoan $(0.9 \mathrm{~g}$.) was reconstituted with dilute Ringer phosphate medium $(30 \mathrm{ml}$.) and the resulting enzyme preparation distributed equally among three flasks. The first flask was flushed with $\mathrm{N}_{2}$ and the contents were incubated anaerobically with $\left[{ }^{14} \mathrm{C}\right]$ squalene $\left(2 \times 10^{5}\right.$ disintegrations/min.). The other two flasks were incubated aerobically, but in one case the cyclase was inactivated by boiling for $2 \mathrm{~min}$. before the addition of the $\left[{ }^{14} \mathrm{C}\right]$ squalene. This latter served as a control.

After a period of $3 \mathrm{hr}$. the incubations were terminated by the addition of an ethanol-diethyl ether mixture and worked up in the usual manner (cf. Cornforth et al. 1959). The yields of [14C]tetrahymanol were determined after two chromatographic purifications. For the anaerobic, aerobic and control experiments these were respectively $3 \cdot 0,2 \cdot 6$ and $0.05 \%$.
From these results we draw the following conclusions: (a) As with the living organism (Caspi et al. 1968), a disrupted cell preparation of Tetrahymena pyriformis converts squalene directly into tetrahymanol (Ia). Again, squalene 2,3-oxide is not involved as an intermediate. (b) The enzyme system in question retains its activity after the protozoa are freeze-dried. (c) No interconversion of squalene and squalene 2,3-oxide takes place in this system, since each of these on reisolation retain their isotopic purity. (d) The oxygen atom of tetrahymanol does not appear to be derived from atmospheric oxygen. This is in accord with the postulated mechanism (Tsuda et al. 1965; Caspi et al. 1968) for the biosynthesis of tetrahymanol from squalene.

This work was supported by the American Cancer Society (Grant P-500G), The National Science Foundation (Grant GB5832) and the National Institutes of Health (Grant CAK3 16614-06).

Barton, D. H. R., de Mayo, P. \& Orr, J. C. (1958). J. chem. Soc. p. 2239.

Bowden, K., Heilbron, I. M., Jones, E. R. H. \& Weedon, B. C. L. (1946). J. chem. Soc. p. 39.

Budzikiewicz, H., Djerassi, C. \& Williams, D. H. (1967). Mass Spectrometry of Organic Compounds, 1st ed., p. 98. San Francisco: Holden-Day Inc.

Caspi, E., Zander, J. M., Greig, J. B., Mallory, F. M., Conner, R. L. \& Landrey, J. R. (1968). J. Amer. chem. Soc. $80,3563$.

Clayton, R. B., van Tamelen, E. E. \& Nadeau, R. G. (1968). J. Amer. chem. Soc. 90, 820.

Corey, E. J., Russey, W. E. \& Ortiz de Montellano, P. R. (1966). J. Amer. chem. Soc. 88, 4750.

Cornforth, J. W., Cornforth, R. H., Pelter, A., Horning, M. G. \& Popják, G. (1959). Tetrahedron, 5, 311.

Goad, L. J. \& Goodwin, T. W. (1966). Biochem. J. 99, 735.

Godtfredsen, W. O., Lorck, H., van Tamelen, E. E., Willett, J. D. \& Clayton, R. B. (1968). J. Amer. chem. Soc. 90, 208.

Halsall, T. G. \& Aplin, R. T. (1964). Fortschr. Chem. org. Naturst. $22,153$.

Hogg, J. F. \& Kornberg, H. L. (1963). Biochem. J. 86, 462.

Mallory, F. B., Gordon, J. T. \& Conner, R. L. (1963). J. Amer. chem. Soc. 85, 1362.

Rees, H. H., Goad, L. J. \& Goodwin, T. W. (1968). Tetrahedron Lett. no. 6, p. 723.

Ryley, J. F. (1952). Biochem. J. 52, 483.

Tsuda, Y., Morimoto, A., Sano, T., Inubushi, Y., Mallory, F. B. \& Gordon, J. T. (1965). Tetrahedron Lett. no. 19, p. 1427.

van Tamelen, E. E. \& Curphey, T. J. (1962). Tetrahedron Lett.no. 3, p. 121.

van Tamelen, E. E., Willett, J. D., Clayton, R. B. \& Lord, K. E. (1966). J. Amer. chem. Soc. 88, 4752. 